\title{
AN EVENT OF CURIOSITY: WHEN A MERMAID FAKE CRAWLED ON A TV-SCREEN
}

\section{Pilvi Vainonen}

\section{Curious things can happen when we put together two mysterious mermaid fakes from the South Sea, two imaginary American FBI agents, and an ordinary Finnish museum worker. In an extraordinary way, this combination gave rise to some clues which led to some detective work concerning the origins of the two mermaid fakes in the National Museum of Finland.}

Once upon a time Sea Captain O.W. Lindholm was sailing along the Australian shore and in one coastal village he was shown a strange creature, half anthropomorphic, half fish. He was told that it had drifted dying to the beach some time ago. Although he had never seen such a monster before he knew immediately what it was: a small but terrifying mermaid. He bought it and kept it as a horrible souvenir.

All this is fantasy. What we really know about Captain Lindholm is that he was an amateur naturalist and used to collect specimens for the Zoological Museum of the Alexander University of Helsinki. Sometime between the years $1860-63$, probably in 1860 , he returned to Finland and donated a large number of specimens to the Zoological Museum. The collection included «...28 sp. snakes and lizards, 44 sp. fish, a broader collection of lower animals including shells from different regions, especially from the South Sea Islands and
Japan..» (Accounts 1863). And even though it is not mentioned separately, it is known, that among these specimens was a $35 \mathrm{~cm}$ long fake mermaid.

In 1867 the Zoological Museum moved the mermaid Lindholm had brought to the University's ethnographical collections and a labelled it artificial. There this ugly but impressive «sea animal» with long pointed nails and sharp teeth in its gaping jaws, set in a floating posture, was thought to be a fetish. The humanoid head and arms were presumed to be the upper body of a monkey, while the lower part is undoubtedly fish. The whole body is hard and dark brown. The ribs, the vertebrae of the backbone and the shape of the skull can clearly be seen under the stretched, dried skin.

The ethnographical collections of the University moved in to the new National Museum of Finland in 1912. And finally, having spent over 65 years alone in storage, far from home, the mermaid received a 


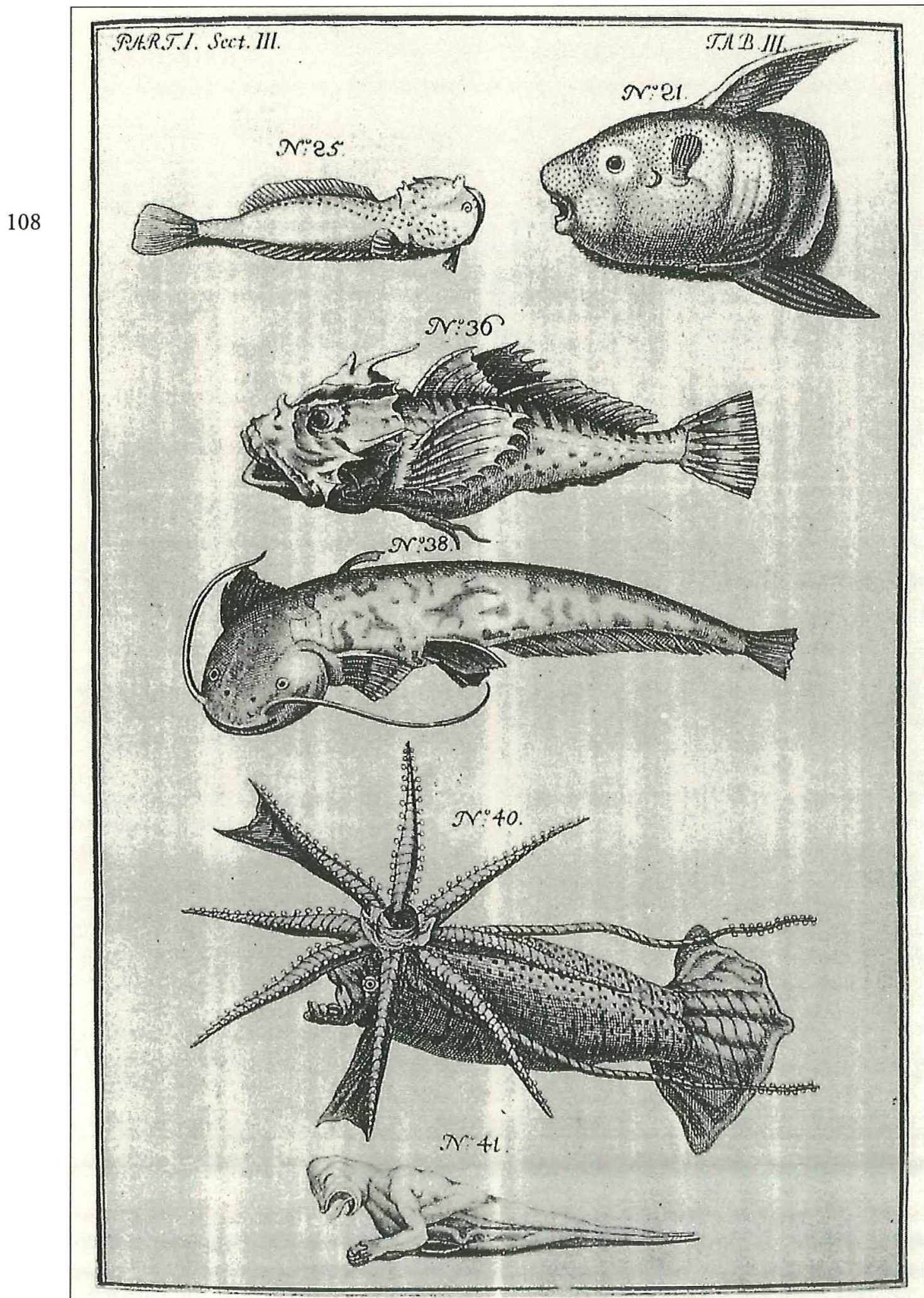




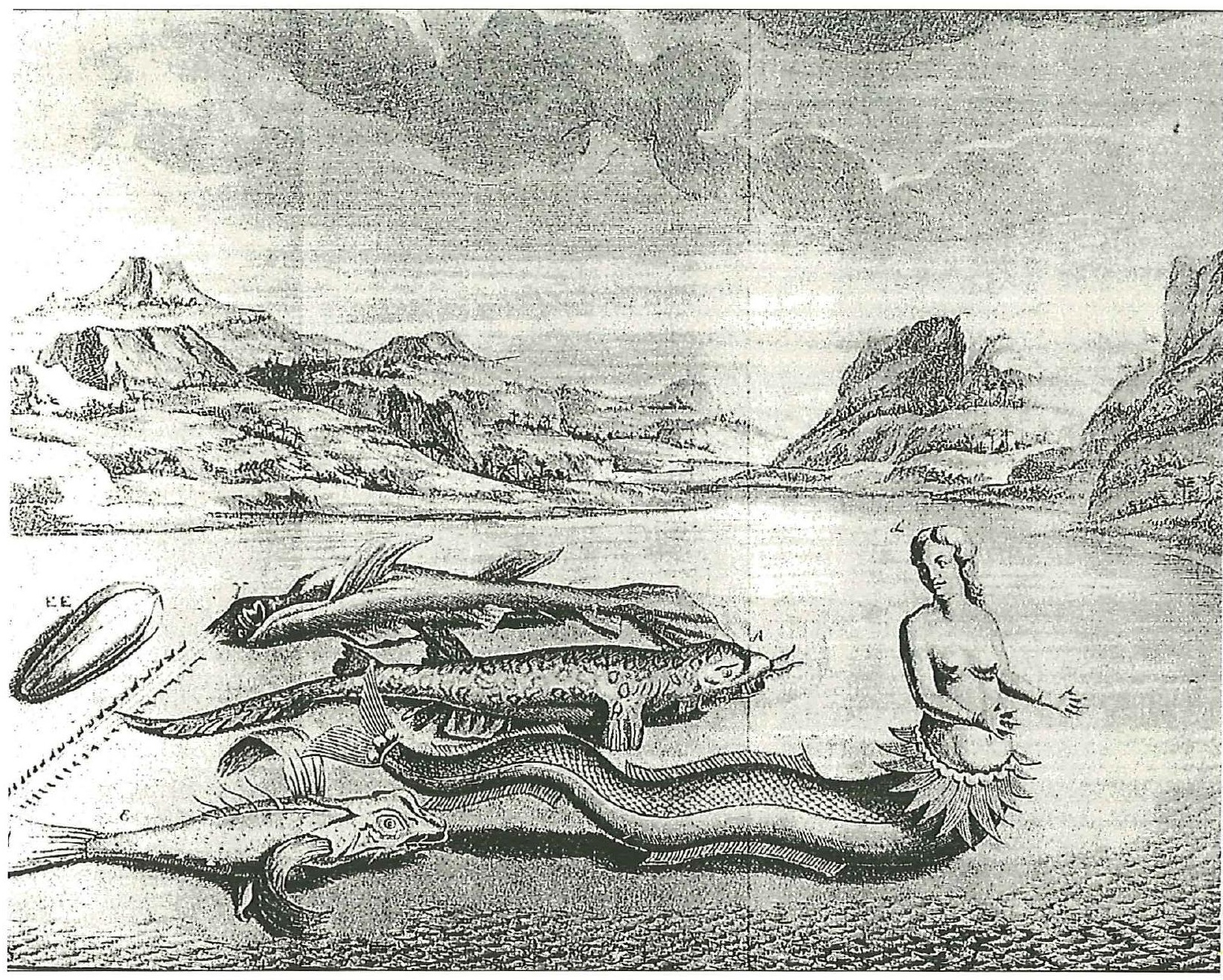

Mermaid and fishes in a copper engraving from Francois Valentijn's Oud en Niew Oost-Indien, 1724-26.

companion: in 1925 another fake mermaid sailed in. It was moved from the Helsinki City Museum along with 92 other articles. Its route and when it arrived in Finland are unknown. Its appearance greatly resembles the floating mermaid, except that there are some differences in teeth, nails and skull, and it has slender tufts of hair on its skin. The posture is also different: this one seems to be crawling as if it had been desperately trying to escape at the moment of its death.

\section{THE OPENING OF THE X-FILE}

Indeed today the mermaid couple still look incredibly wild. "When we wanted to spook somebody we show it to them", said Kaisa Grönholm from the Exotica collections of the National Museum. In the summer 1996 there was an opportunity to spook a wider public, since Exotica participated in an exhibition of curiosities in Helsinki. Curious and furious as they are, it was decided to put the the mermaids on display. I worked in Exotica at that time and was also introduced to them. At first I was stunned, then overjoyed. Irrationally, it was difficult to believe that they were really man-made.

But the real shock came a few weeks later. I was watching The X-Files on TV - an American cult series which I hadn't seen before - and suddenly a drawing portraying a crawling mermaid fake appeared on the screen. It seemed to be very similar to the 
two mermaids in the National Museum. The main characters, FBI agents Scully and Mulder, were told (and I also was listening most carefully) that it was a mermaid fake made of a mummified monkey and a fish, and a certain Barnum Circus had displayed it in the USA in the 19th century. It was called the "Fidzi mermaid".

A mummified monkey? This was already the second hint that monkeys were involved. Whose fantastic idea had it been to join together a mummified monkey and a fish? Who had made these mermaids? All kinds of questions arose in my mind. Luckily, Phineas T. Barnum, the late director of the American Museum in New York, was able to answer some of them.

\section{MONKEY BUSINESS}

P.T. Barnum relates in his autobiography that he had hired the Fidzi or "Feejee" mermaid from a man, who in turn had bought it from a poor sailor. The father of this sailor had been a sea captain - just like O.W. Lindholm - and had bought the mermaid in Calcutta from some Japanese sailors in 1822. The captain had believed so firmly in the authenticity of the mermaid that he had paid 6000 US dollars for it. Unfortunately, the money belonged to the shipping company, which was not equally sure about the mermaid. The poor captain had to work without wages for the rest of his life, and when he

The half human, half bird Sirens of Greek mythology are close relatives to mermaids.

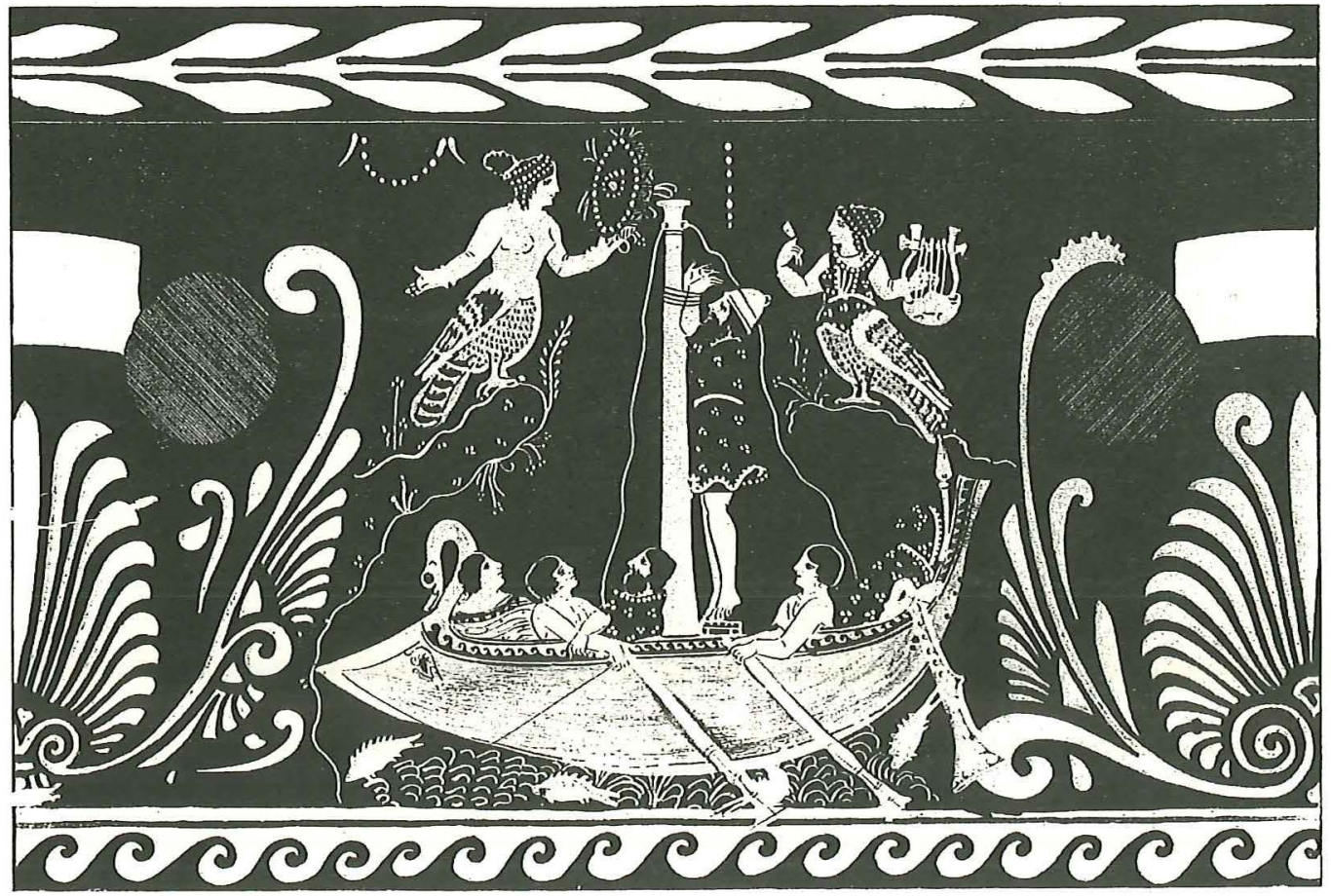




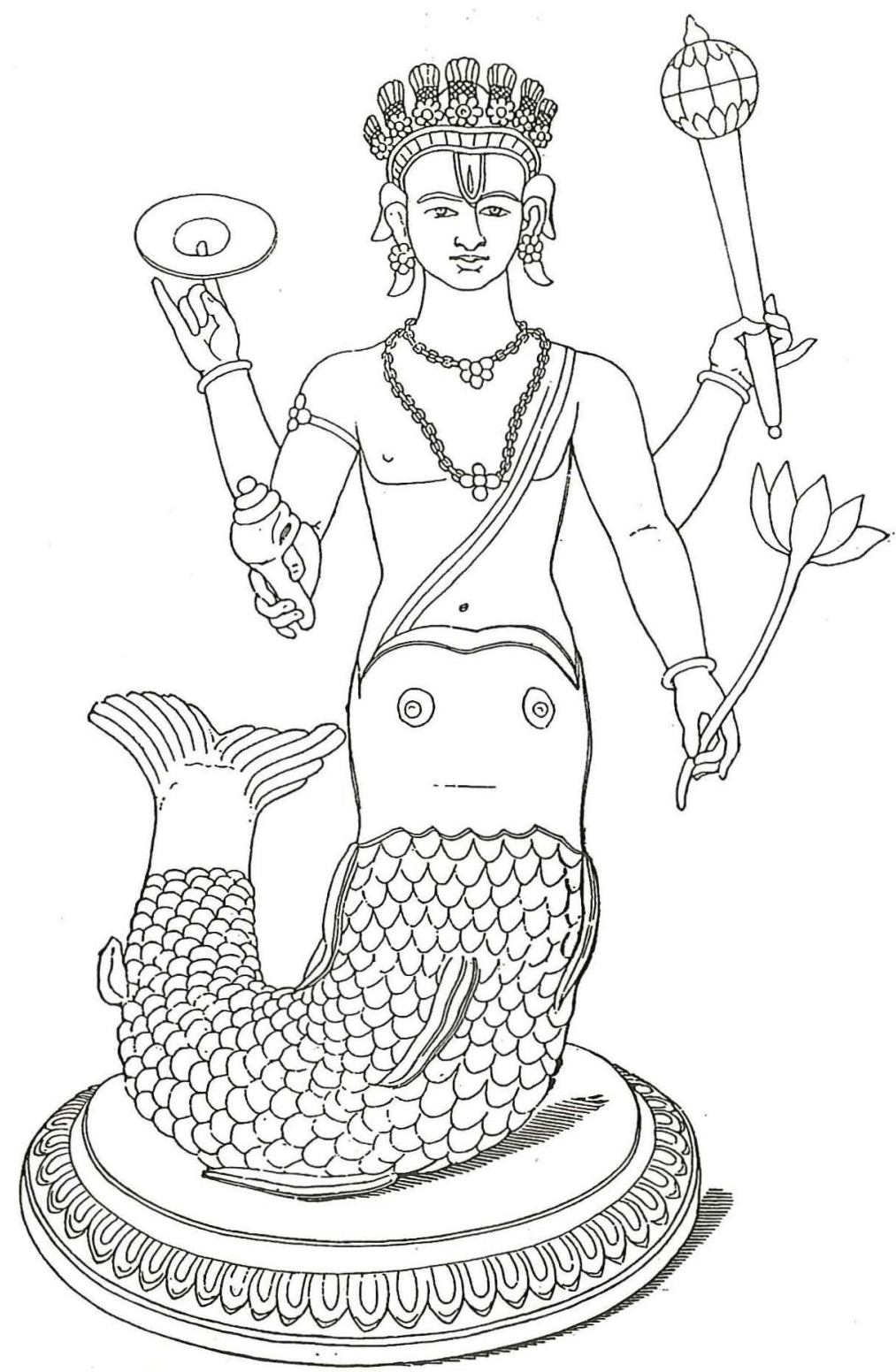

A merman from India. The Matsya or "fish" is an incarnation of the Hindu god Vishnu.

died he left his sailor son nothing but the dried-up mermaid. But in Barnum's hands the creature turned into a goldmine. In 1842, in conjunction with the greatest and the most crooked advertising campaign ever seen, he put it on display as a real mermaid in the New York Concert Hall for one week, and then in his own American Museum. For several weeks peo- ple lined up to see it, and after this success in New York it set out on a tour in USA.

Barnum was the leading clue in my investigations. More than a hundred years after his death he helped to tame our two mermaids. Apart from his autobiography, Barnum led me to a number of other sources, including P.F. von Siebold's important book which describes life in 
112 Japan at the beginning of the 19th century. Von Siebold tells a story he had heard about a clever fisherman, who neatly united the upper half of a monkey to the lower half of a fish. The man had told people that he had himself caught the creature alive in his net, but that it had died shortly after being taken out of its natural element. The most elaborated detail in the story is that this half-human fish had made a religious prediction before it died.

This Japanese fisherman also made a lot of money out of his monster, so we must conclude that the Americans were not the only ones clever at humbug. It is known that these kinds of mermaid fakes were manufactured in other parts of East Asia, Melanesia and western Polynesia as well, but perhaps Japan was the cradle: "The sale of these pictured mermaids was im- mense. Either this composite animal (made by the fisherman), or another, the offspring of the success of the first, was sold to the Dutch factory (in Japan) and transmitted to Batavia, where it fell into the hands of a shrewd American, who brought it to Europe, and there, in the years 1822-3, exhibited his purchase as a real mermaid at every capital, to the admiration of the ignorant, the perplexity of the learned, and the filling of his own purse.» (Von Siebold 1981, 185.)

\section{ANATOMICAL INVESTIGATIONS}

Exhibiting 'real mermaids', or at least fragments of real mermaids, is however an even older phenomenon. In his book a Baroque literate, Athanasius Kircher, discusses the

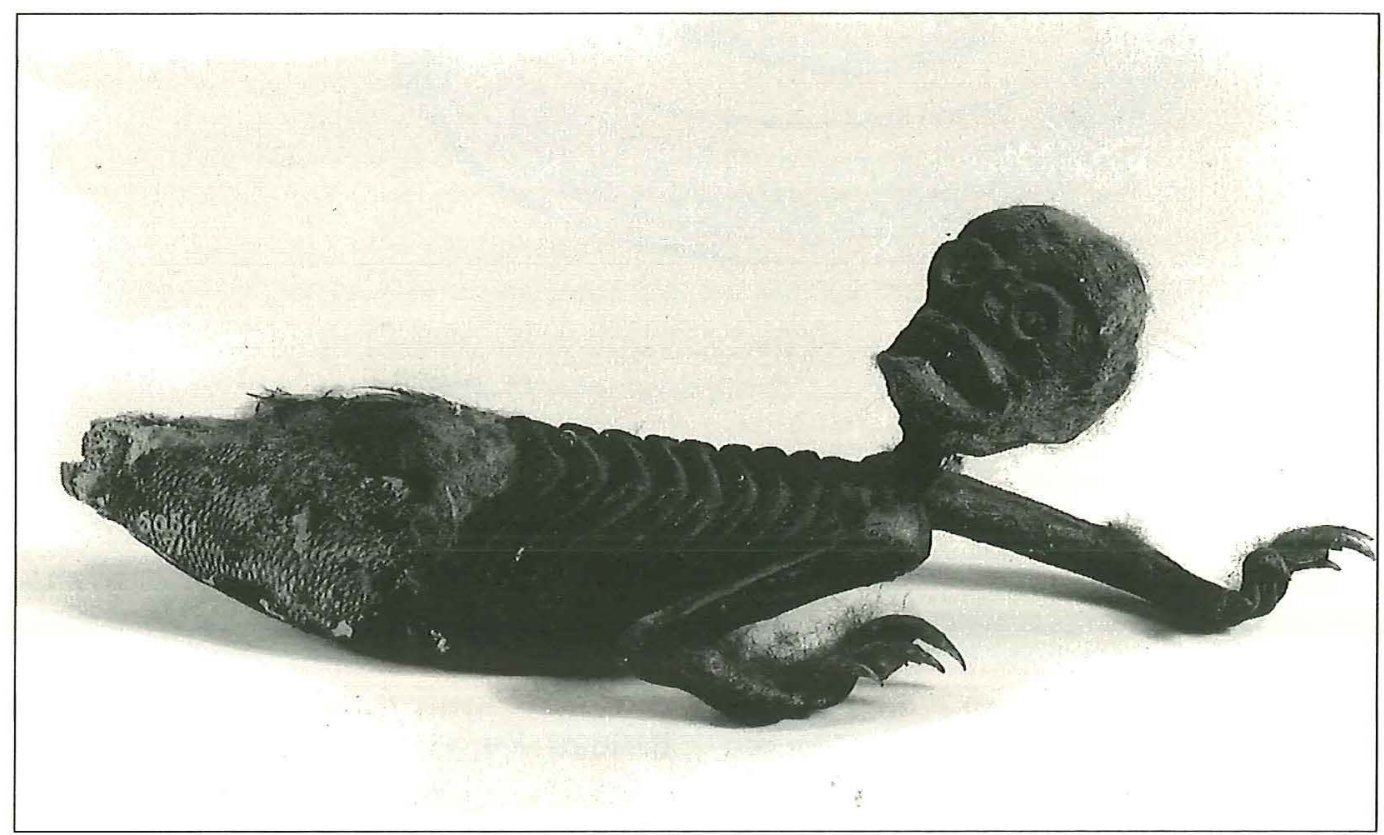




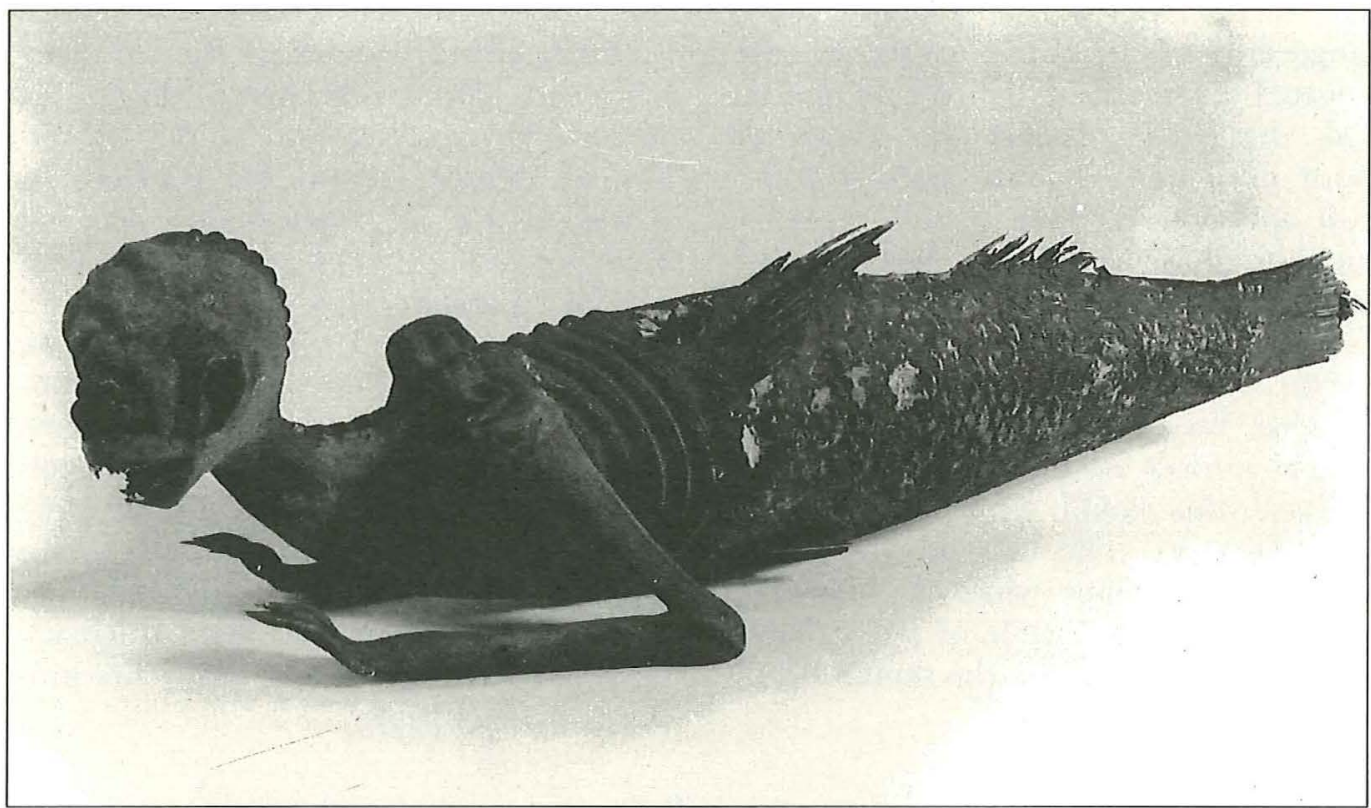

These two mermaid fakes belong to the collections of the National Museum of Finland.

Photo: Ritva Bäckman 1996.

role of mermaids in Noah's ark, and writes that many museums exhibit the tails and bones of these amphibians. It was said that the bones had a marvellous power to staunch bleeding. (Goodman 1983, 43.) The curiosity cabinets flourished in the middle of the 16th century and in this early period exotic, odd and monstrous examples were collected as illustrations of God's warning to pious people through the creation of such unnatural beings.

But it is certain that the motives of the manufacturers of the mermaid fakes were not at all so pious. Apparently older than the monkey-fish combinations are the fakes made of rays, skates and other cartilaginous fish, which have been manipulated to produce either anthropomorphic or dragon-like creatures. For an unknown reason these fakes are called Jenny Hanivers, and they were probably manufactured in Europe. Sometimes they are called, paradoxically, "Sea Bishops", because the pectoral wings of the fish have been variously manipulated to give the appearance of an ecclesiastical garment. (Jones et al. 1990, 85-6.)

But all bubbles burst sooner or later. While the Fidzi mermaid was on tour in 1843, discussion concerning its originality grew louder. In general, the atmosphere was propitious for this kind of debate, since the supporters of black slavery stood up for the divine plan and argued that different races had been created at separate times and formed distinctive species. Who could say that God had not also created mermaids? In Charleston a group of dis- 
114 tinguished scientists and naturalists investigated the mermaid, defied God and stated, that "the mermaid was simply the body of a monkey sown together with a fish and done with very little regard to anatomical accuracy, since there were present two chests and two abdomens" (Harris 1973, 65-66).

Our two mermaids began to feel more familiar. Yet I was eager to know the species of animals used in their manufacture, because this could help to locate the manufacturers. The tails were not from skates or rays, but what? And had the upper bodies been made of two different kind of monkeys, since the skulls and the teeth were different?
Distinguished researchers Roni Andersson and Mikko Haaramo from the Natural History Museum of the University of Helsinki solved the problem by revealing, that the upper bodies were not from any kind of monkey at all, they were just fake monkeys. How clever: if we don't have a mermaid, let's make one. And if we don't have a monkey, let's make a monkey! The teeth and the jaws of the floating mermaid are from a lizard, and its nails are the quills of a porcupine. The crawling mermaid's jaws and teeth as well as the tails of both fakes are from sea perch. The nails of the crawling mermaid originally belonged to a fowl. Their 'skins' are probably made of paper.

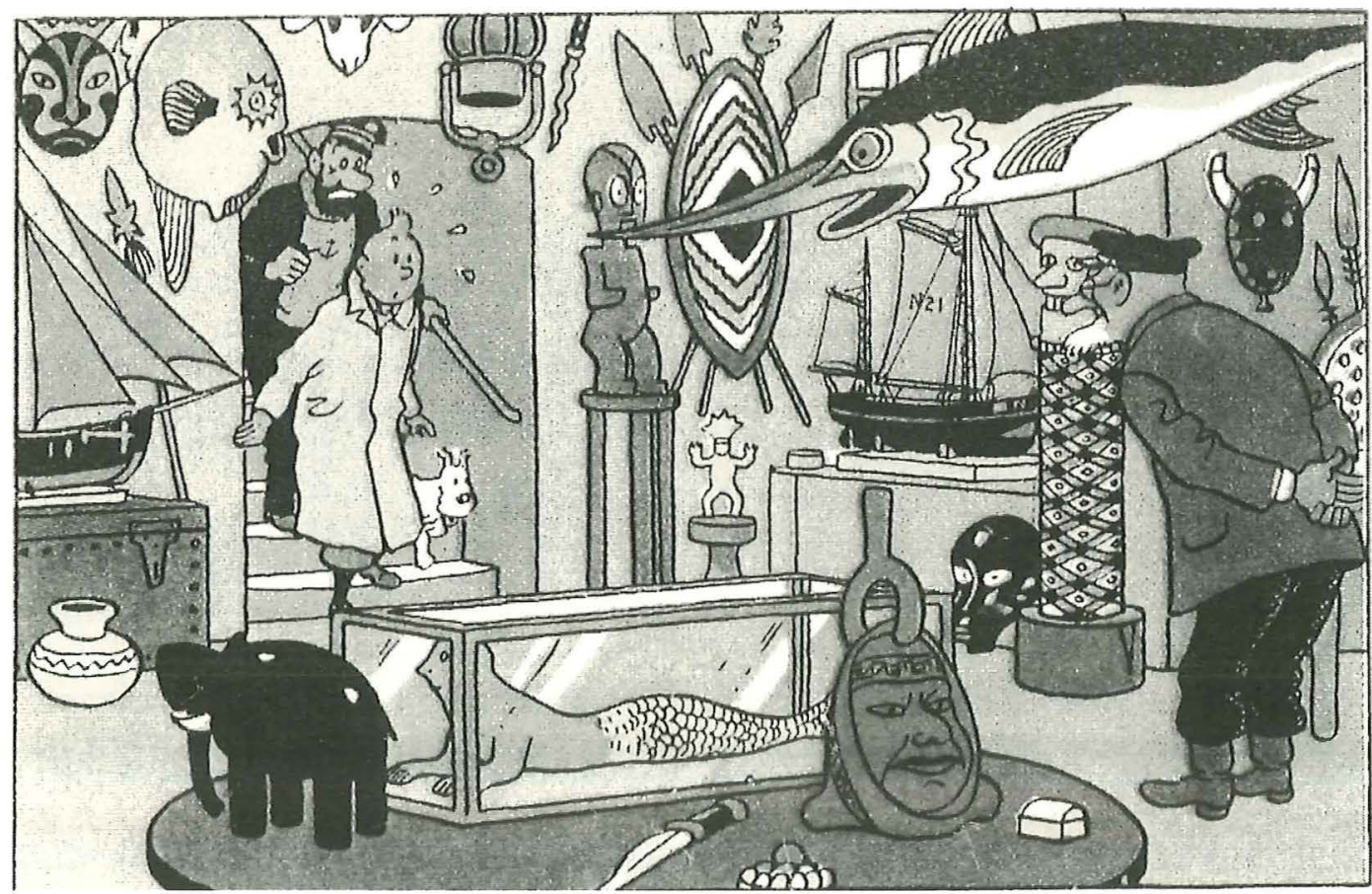

Captain Haddock and Tintin came across a mermaid fake in a maritime shop in Paris. Hergé 1944. Le Trésor de Racham le Rouge. 


\section{BETWEEN CULTURE AND NATURE}

It is no wonder that people started to materialize mermaids, originally products of non-material culture, since different kind of water spirits and beings have always been found in the mythology of peoples living on riverbanks, coastal areas and archipelagoes. Besides, it is not just a question of believing, it is also known that people have actually seen Sirens and mermaids!

Christopher Columbus himself saw three mermaids cavorting off the coast of Hispaniola in 1493. The dead body of a Siren called Parthenope was found washed ashore in Campania and was buried there. She gave her name to the city of Naples. In the 6th century, a mermaid was caught and baptized in northern Wales. Another, in 1403, slipped through a breach in a dike and lived in Haarlem until the day of her death. Nobody was able to understand her speech but she was taught to weave and she worshipped the cross as if instinctively. (See Houlberg 1996, 32; Borges 1987, 132-3.)

Mermaids have many kind of relatives, forefathers and 'foremothers' in different cultures. The closest of them seems to be the Greek Sirens. In Indian mythology there are the heavenly nymphs, the Apsaras. The sanskrit name 'Apsara' means 'moving in the water'. The singing and playing of the Apsaras charm passers-by, and their sexual behaviour is rather loose. These characteristics indicate a close historical relationship between Apsaras, Sirens and mermaids. There are also many other spirits and demigods for example in African, Philistinean, Babylonian and Sumerian mythologies, both female and male, who have given their charasteristics to the mermaid. (See e.g. Benwell \& Waugh 1961; Goodman 1983; Houlberg 1996.)

The nature of mermaids is ambiguous, since there are two conflicting characteristics attributed to them. On the one hand there is the sweetness and the promise of love, and on the other danger and death. Their nature overlaps the categories of culture and nature: it is a feature common to both Sirens and mermaids that they use their calculating human heads and brains at the same time as their animal-like sexuality, caused by their animal lower bodies, to entrap poor sailors. And they never keep their promises.

We have seen that mermaid fakes also can cause trouble. Even if there is nothing sensuous in these particular fakes, one can believe that if they were more natural than cultural, if they were God's creations and not products of human skill, they would surely be dangerous, if not charming. They would be ready to bite an innocent swimmer with their nail-like teeth, or as a well-organized group to attack a canoe or a boat, and having succeeded in causing a shipwreck they would have had a feast at the cost of the unfortunate fishermen or sailors...

\section{EPILOGUE}

This is how we learned more about our two little mermaids, combinations of perch and fake monkeys. However, the question remains unanswered of how the manufacturing of these fantastic fakes spread over so vast an area as it seems to have done and of what kind of people the manufacturers really were. What did they really think about their products? Did 
116 they compete over whose mermaid looked most fearful? The story of the Japanese fisherman is the only account I have found to date concerning the living people behind these skilfully made artifacts. To cite The X-Files: "The truth is out there....... and here, the curiosity remains.

\section{ACKNOWLEDGEMENTS}

I'd like to thank all who have helped to trace the origins of the mermaid fakes, especially Roni Andersson and Mikko Haaramo from the Natural History Museum of the University of Helsinki; Sergio Ocambo, student of cultural anthropology at the University of Helsinki; Heli Lahdentausta, Pirjo Varjola, Kaisa Grönholm and Marjatta Parpola from the Exotica collections of the National Museum of Finland; and Aila Viholainen, the pioneer of mermaid studies in Finland.

\section{REFERENCES AND LITERATURE}

Barnum P.T. 1888. Life of P.T. Barnum Written by Himself. The Courier Company Printers, Buffalo.

Benwell Gwen and Arthur Waugh 1961. Sea Enchantress. The Tale of the Mermaid and her Kin. Hutchinson, London.

Borges Jorge Luis 1987 (1967). The Book of Imaginary Beings. Penguin Books, Harmondsworth.

Dance S. Peter 1978. The Art of Natural History. The Overlook Press, Woodstock.

Dictionary of American Biography Vol. I 1928. Humphrey Milford, Oxford University Press, New York.

Goodman Ailene S. 1983. The Extraordinary Being: Death and the Mermaid in Baroque Literature. Journal of Popular Culture Vol. 17 No. 3 Winter 1983 p. 32-48.
Greenberg Kenneth S. 1990. The Nose, the Lie, and the Duel in the Antebellum South. The American Historical Review Vol. 95 No. 1 February 1990 p. 57-74. American Historical Association.

Harris Neal 1973. Humbug. The Art of P.T. Barnum. Little, Brown and Co., Boston.

Houlberg Marilyn 1996. Sirens and Snakes. Water Spirits in the Arts of Haitian Vodou. African Arts Spring 1996 p. 30-35.

Jones Mark, Paul Craddock and Nicolas Barker (eds) 1990. Fake? The Art of Deception. Trustees of the British Museum, London.

Leikola Anto 1992. Seireenien taru: syöjätärlinnuista pikku merenneidoiksi. Portti 4/1992 p. 78-85. Helsinki.

Redogörelse for Kejserliga Alexander-Universitetets $i$ Finland 1860-1863. J.C. Frenckell \& Son, Helsingfors.

von Siebold P.R.1981 (1841). Manners and Customs of the Japanese in the Nineteenth Century. Charles E. Tuttle Co., Tokyo.

Vainonen Pilvi 1996. Mistä tulet, merenneito? Kunkausiliite heinäkuu 1996 p. 34-36. Helsingin Sanomat, Helsinki.

Viholainen Aila 1996. Merenneito on toista kuin ihminen. In: Riikka Puronen, Rolf E.A. Nordström and Aila Viholainen, Merenneidot 1996 p. 7-8, 11-12, 15-20. Helsinki.

Werner M.R. 1923. Barnum. Harcourt, Brace and Co., New York.

Pilvi Vainonen, MA, graduated from Department of Cultural Anthropology, University of Helsinki.

Working on doctoral dissertation about how objects are turned into museum objects.

Adr: Linnankatu 5 A 3, FIN-00160 Helsinki 16, Finland Fax +358-940501 